\title{
A FORMAÇÃO DO CONCEITO DE NOME DO PAI (1938-1958)
}

\author{
ROSANE ZÉTOLA LUSTOZA ${ }^{1}$
}

Rosane Zétola Lustoza

${ }^{1}$ Universidade Federal do Paraná (UFPR),

Professora do Departamento de Psicologia, Curitiba/PR, Brasil.
RESUMO: Este artigo discute a formação do conceito de Nome do Pai de 1938 a 1958. Com esse propósito, divide-se a obra lacaniana em 3 etapas. Na primeira, o pai é concebido como imago na tese da primazia do imaginário. $\mathrm{Na}$ segunda, a função paterna é pensada como símbolo na teoria da intersubjetividade. Num terceiro momento, o Nome do pai é formulado como significante na teoria estruturalista. Discutem-se também os limites do conceito do Nome do pai no final dos anos 50 e apontam-se desdobramentos posteriores.

Palavras-chave: Nome do pai; Lacan; simbólico; significante.

ABSTRACT: The formation of the concept of Name of the father (1938-1958). This paper discusses the formation of the concept of Name of the father from 1938 to 1958. For this purpose Lacanian work is divided into 3 stages. At first, the father is conceived as imago in the thesis of the primacy of the imaginary. In the second, the paternal function is thought as a symbol in the theory of intersubjectivity. Thirdly, the Name of the father is formulated as a signifier in the structuralist theory. The paper also discusses the limits of the concept of the Name of the father in the late fifties and points to further developments.

Keywords: Name of the father, Lacan, symbolic, signifier.

DOI - http://dx.doi.org/10.1590/S1516-14982018003004

Todo o conteúdo deste periódico, exceto onde estiver identificado, está licenciado sob uma Licença Creative Commons (cc by 4.0) 
$\mathrm{T}$ ornou-se usual hoje em dia enfatizar a revisão que o último ensino de Lacan impôs à sua chamada primeira clínica, cujo pilar fundamental eram as estruturas organizadas em torno da presença ou ausência do Nome do pai. Um dos pontos paradigmáticos desse debate é a concepção das psicoses em cada período: enquanto na primeira clínica a psicose apareceria sob a ótica do negativo, como ausência daquilo que opera na neurose, na última clínica haveria uma preocupação com as operações que um psicótico pode realizar positivamente. De fato, a necessidade de pensar as inúmeras e diversificadas formas de estabilização na psicose deu margem a um enriquecimento em relação às descrições da primeira clínica, a qual estaria ainda muito balizada pela ausência da função paterna. Através da topologia e da teoria dos nós, pôde-se conceber formas distintas de amarração entre os registros do Nome do pai, passíveis de funcionar como suplência. Haveria uma pluralização dos nomes do pai, ou seja, uma diversificação das formas de ponto de basta, sendo a forma de enodamento típica da neurose apenas uma entre outras.

Tal revisão coloca em jogo um redimensionamento do lugar que a primeira clínica ocupa no ensino de Lacan. A teoria do Nome do pai certamente foi corrigida a partir da teoria dos nós, pois seus limites de validade foram finalmente estabelecidos. Ou seja, as condições dentro das quais a teoria do Nome do pai pode ser considerada como legítima foram determinadas de forma mais precisa pela teoria posterior. Em termos do tratamento analítico, a primeira clínica oferece contribuições preciosas no que concerne às chamadas psicoses extraordinárias, nas quais o desencadeamento é acompanhado por fenômenos de ruptura muito evidentes, tais como alucinações e delírios. Já as psicoses ordinárias, nas quais aparecem fenômenos muito mais sutis e discretos, puderam ser pensadas de forma mais adequada a partir das operações de suplência descritas no Seminário 23 (LACAN, 1975-76/2007).

Evidentemente, na clínica dos nós surgem novas questões que não eram passíveis de emergir dentro do horizonte de problemas posto pela teoria anterior. Contudo, acreditamos que uma nova teoria será tão mais fecunda quanto melhor puder dar conta das questões às quais a antiga teoria respondia satisfatoriamente; e essa é uma das razões que justificam nosso esforço de retornar às bases do conceito de Nome do pai. Além disso, nossa hipótese é que tal conceito continua relevante na clínica da atualidade, pois pode servir de guia que orienta a condução do tratamento tanto em casos de neuroses quanto de psicoses extraordinárias.

O objetivo deste trabalho é pensar a formação do conceito de Nome do pai de 1938-1958, privilegiando alguns dos principais pontos de inflexão do conceito. Devido ao limitado alcance do artigo, não se pretende contrapor tais formulações com as do último ensino de Lacan, mas, antes, destacar as principais teses do período em exame. Supõese que entender a formação do conceito do Nome do pai é tarefa prévia fundamental a fim de que se possa avaliar precisamente o que se mantém e o que foi ultrapassado. Tal tarefa não possuiria apenas um valor histórico ou epistemológico, mas também clínico.

O trabalho abarca a função paterna na obra lacaniana de 1938-1958, conforme 3 escansões: como imago, no âmbito da primazia do imaginário; como símbolo, na teoria da intersubjetividade; e como significante, na teoria estrutural. Na quarta e última seção, serão também apontados alguns impasses a que chegaram as formulações desse período, prenunciando assim os desenvolvimentos posteriores.

\section{1) O PAI COMO IMAGO NA TEORIA DO IMAGINÁRIO}

Em Os complexos familiares na formação do indivíduo, Lacan afirma que a construção do eu (moi) resulta de uma "tendência salutar" (LACAN, 1938/2003, p. 48) presente no psiquismo que visa a busca da unidade, uma vez que a criança evitaria permanecer mergulhada no estado de despedaçamento corporal inicial. Já que a forma mais intuitiva pela qual a ideia de unidade pode aparecer para o infans é a imagem visual, será pela contemplação da imagem do semelhante que o eu se organizará como gestalt: "é através do semelhante que o (...) eu se realiza: quanto mais pode assimilar de seu parceiro, mais o sujeito reforça sua personalidade e sua objetividade, garantes de sua eficácia futura" (ibidem, p. 51).

Uma vez que o semelhante é necessário como modelo indutor da formação do eu, nesse primeiro momento reina uma indistinção entre o eu e o outro que não provoca muitos conflitos. Será apenas com a instalação da situação triangular que o conflito eclodirá, ou seja, quando ambos os parceiros se derem conta que disputam o amor 
de um terceiro - no caso, a mãe. No drama do ciúme, o sujeito percebe o irmão como um intruso que recebeu mais do que ele, ou que tomou o que é dele; constatação dolorosa, que inaugura a agressividade típica do registro especular. Um impasse se desenha: se, por um lado, o sujeito deve amar o irmão enquanto modelo, por outro, deve odiá-lo enquanto obstáculo.

O pai está fadado a aparecer nesse contexto também como um intruso; se isso é verdade, o que o qualificaria a ocupar mais tardiamente um novo lugar junto à criança? Lacan evocará aqui a famosa resposta freudiana, segundo a qual o sujeito abre mão de seus impulsos agressivos ou eróticos porque aceita se render à superioridade esmagadora do rival adulto. Ou seja, apesar da "agressividade contra o genitor em relação ao qual seu desejo sexual o coloca na posição de rival" (ibidem, p. 54), o sujeito acaba dispensando ao pai tratamento diferente do que concedeu aos irmãos, renunciando então às suas pretensões à mãe devido ao "temor secundário, experimentado em contrapartida, de uma agressão similar" (idem). O sacrifício das pulsões se dará na medida em que a suposição da potência superior do pai gerar no filho o temor de uma retaliação.

Ressalte-se aqui que a superioridade esmagadora do pai não necessariamente é um reflexo do que ocorre na realidade factual; contudo, basta que ela opere como suposição para que seus efeitos se implementem na realidade. O pai se credencia a partir daí como imago norteadora, na qual o sujeito se inspira tanto para renunciar às suas pulsões (recalque) quanto para dar um novo destino a elas (sublimação).

É nesse ponto que Lacan fará um importante apontamento sobre a função do pai: um grupo familiar desfalcado do pai, reduzido, portanto, à mãe e à fratria, ficaria inteiramente imerso numa realidade imaginária, formando assim uma condição muito favorável à eclosão da psicose (LACAN, 1938/2003, p. 51). Evidentemente, chama a atenção, nessa passagem, a necessidade da presença do pai como suporte da função paterna, sinalizando o quão distante se está da formulação do conceito de Nome do pai como significante. Vale notar também que, mesmo desprovido do conceito do Outro simbólico, Lacan já intui a necessidade de fazer do pai uma instância que introduz um novo registro, ao impedir o aprisionamento do grupo familiar em uma realidade imaginária.

Ao propor a presença do pai como imprescindível, Lacan aqui não recai na posição ingênua de tomar a imago paterna como um decalque ou uma réplica do pai da realidade empírica. Até porque Lacan já sabe que a apreensão da realidade jamais se dá de forma direta ou imediata, ocorrendo sempre um componente de distorção aportado pela realidade psíquica. A noção de imago vem em seu socorro justamente por representar uma espécie de protótipo mental que modela as experiências e que informa os conteúdos objetivos. A imago paterna permitirá a Lacan sustentar a ideia de que a função possa funcionar bem, mesmo que as figuras responsáveis por suportá-la na realidade estejam muito pouco à altura de sua tarefa. É por essa razão que, apesar de admitir uma certa decadência do pai, ele afirma que "não estamos entre os que se afligem com um pretenso afrouxamento dos laços de família" (ibidem, p. 66).

A certa altura do texto, o pai contemporâneo é descrito como uma figura humilhada, carente, postiça. Ora, até para poder situar o pai como deficitário, está claro que é preciso comparar a sua imagem com a daquilo que ele deveria ser; pois é somente em contraponto à imagem de um pai potente ou idealizado que o pai atual pode aparecer como faltoso. É a imagem idealizada do pai que condena as outras imagens da série à inferioridade, à condição de pálidos reflexos da imagem primitiva. Por essa razão, supomos que, nesse texto, a função paterna se traduz por uma duplicação imaginária do pai: existiria em nós uma imagem idealizada do pai, à qual estamos inconscientemente fixados e pela qual medimos a imagem do pai atual, ora no sentido de superestimá-la, ora no de denegri-la.

Na duplicação imaginária do pai, fica insinuado ou implícito algo que será desenvolvido apenas mais tarde: a função paterna não se confunde nem com a imagem do pai decadente, nem com sua imagem idealizada, pois ela será antes a condição que torna possível a comparação entre as imagens, permitindo-nos comparar o que é (uma imagem existente) com aquilo que não é (uma imagem inexistente). Somente o símbolo permitirá ao sujeito o poder de comparar as imagens entre si; sem a mediação da palavra, as imagens careceriam de um princípio organizador que possa lhes atribuir valor. Esse será um segundo momento da elaboração lacaniana, no qual o imaginário é colocado em sujeição ao simbólico, o que destacamos a seguir. 


\section{2) O PAI COMO SÍMBOLO NA TEORIA DA INTERSUBJETIVIDADE}

Lacan (1953-54/1983) já destacava a importância da ordem simbólica antes mesmo de fazer uma aliança mais profunda com a linguística estrutural, portanto ainda dentro do quadro de uma teoria da intersubjetividade. A tese da intersubjetividade supõe que a psicanálise deveria levar em conta - como critério de verdade na praxis clínica - não os fatos observáveis, mas a realidade tal como nasce no interior da relação entre os sujeitos. Estribado em referências à fenomenologia, ao existencialismo e ao hegelianismo, Lacan será levado a pensar a função do símbolo como elemento mediador que organiza a relação imaginária entre os sujeitos.

Quando um sujeito declara ser pai de alguém, o qual aceita simultaneamente o papel de filho, ocorre um pacto simbólico, graças ao qual as características anteriores dos dois protagonistas serão apagadas: doravante, eles nunca mais serão os mesmos que eram antes do contrato. "O símbolo introduz um terceiro elemento de mediação, que situa as duas personagens em presença, as faz passar a um outro plano, e as modifica" (ibidem, p. 182). Isso porque a inscrição simbólica em um determinado lugar gera consequências imprevisíveis para o sujeito, cuja existência será transformada de uma forma que não está sob o controle do seu eu (moi). Aceitar ser pai, por exemplo, é assumir que a sua palavra terá peso sobre os seus filhos, mas de uma forma cujos desdobramentos não podem ser inteiramente conhecidos a priori, pois dependem de ressignificações levadas a cabo não só pelo filho, mas também pelos outros parceiros da comunidade humana.

Nesse contexto, a palavra vazia é aquela que amortece os efeitos da intervenção do simbólico, pois leva o sujeito a recusar tais efeitos. Por exemplo, sou pai, mas nego a importância das minhas falas sobre as crianças. Já a palavra plena é a transformação operada pelo símbolo, pela qual o sujeito assume um mandato simbólico ao qual sua subjetividade se engajará. Aqui, está em jogo a assinatura pelo sujeito de um contrato cujas cláusulas não são inteiramente conhecidas, mas por cujas consequências ele deverá responder.

A ordem simbólica implica que o sujeito seja colocado sob condições que ignora, submetendo-se a um sistema que o ultrapassa. Para ilustrar esse ponto, Lacan forja o exemplo extremo de uma criança muito pequena que ainda não acedeu à fala, filha de um pai já senil:

Antes mesmo que eu esteja em condições de pronunciar as palavras pai e filho, e mesmo se ele está gagá e não pode mais pronunciar essas palavras, todo o sistema humano em volta já nos define, com todas as consequências que isso comporta, como pai e filho. (LACAN, 1953-54/1983, p. 183, grifo meu).

Não há aqui proporcionalidade ou simetria: o sujeito depende do sistema simbólico, enquanto o sistema simbólico não depende dele. "Todos os seres humanos participam do universo dos símbolos. Estão incluídos aí e o suportam, muito mais do que o constituem. São muito mais os suportes do que os agentes (ibidem, p. 184). O sujeito vira um suporte mortificado do símbolo.

Se as teorias da intersubjetividade em geral afirmam que a realidade é construída a partir da relação entre sujeitos, Lacan introduz um desequilíbrio no qual o peso da balança penderá mais para um dos pólos da relação, instaurando uma intersubjetividade sui generis. Se os pólos da relação são sujeito e alteridade, é preciso dizer que a alteridade tem um papel determinante maior no reconhecimento do sentido. Em virtude desse fato, Lacan (195455/2010) será levado mais tarde a grafar o Outro com maiúscula, nomeando-o como Outro simbólico a partir do Seminário 2.

Para que a palavra do sujeito possa dar à luz um ser, para que eu possa me fundar em minha realidade de filho, por exemplo, é preciso fazer um desvio pela autorização do Outro - no caso, o pai ou os outros sujeitos da comunidade humana. Por isso, o modelo da fala verídica é Tu és minha mulher: somente quando reconheço o Outro em sua dimensão fundacional, posso eu advir como portador de uma identidade. Minha fala não é por si só uma revelação do ser, a não ser que inclua o Outro como uma instância capaz de legitimar o lugar que ocupo. Só posso ser rei se sou reconhecido pelos meus súditos; só posso ser súdito se reconhecer o rei. Há aqui uma relação assimétrica (pois, para se fundarem em sua identidade os sujeitos precisam fazer o desvio pela mediação de um 
Outro que os reconheça), porém recíproca (o que faz para mim o papel do Outro também é um sujeito, ele também depende de mim e dos outros, que nos tornamos então seu Outro).

A partir dessas elaborações, como a função paterna poderia ser pensada? Já no Seminário 1, Lacan (195354/1983) pensa a função reguladora do pai não mais pela via de uma imagem norteadora, mas, sim, pela via do símbolo. O legado mais importante de um pai passa a ser proporcionar ao sujeito a identificação a uma lei transmitida através da palavra. O sujeito fará da lei transmitida pela palavra paterna a sua lei. Tal processo é denominado introjeção, que Lacan ressalta tratar-se de um processo eminentemente simbólico. O conceito de introjeção simbólica permitirá a Lacan conceber a ponte que liga o interno ao externo, pois esse símbolo internalizado será também o ponto que torna possível uma abertura do sujeito para a alteridade.

A palavra permite ressituar a relação imaginária, conectando os significados primeiros dados pelos seus protagonistas a uma rede mais ampla de significações. Isso ocorre porque "a palavra não tem nunca um único sentido, o termo, um único emprego. Toda palavra tem sempre um mais-além, sustenta muitas funções, envolve muitos sentidos" (LACAN, 1953-54/1983, p. 275). As significações particulares estarão sujeitas a remanejamentos feitos por códigos cada vez mais gerais. Lacan chamará de lei exatamente esse "campo humano universalizante de significações" (ibidem, p. 221), graças aos quais conteúdos particulares podem ganhar sentidos novos e mais extensos. As experiências privadas e idiossincráticas são gradualmente transformadas em algo público e socializável.

Como se sabe, o conceito de Nome do pai será fruto de uma laboriosa construção, começando a tomar forma desde o Seminário 3 (LACAN, 1955-56/2002). Justamente porque esse seminário é um ponto de transição no qual Lacan abandonará a teoria da intersubjetividade em prol da teoria do significante, é possível retirar dali uma belíssima afirmação que condensa e sumariza toda essa formulação anterior sobre a função do pai como símbolo: 0 drama edípico é "uma dramatização essencial pela qual entra na vida um exceder interior do ser humano - o símbolo do pai" (ibidem, p. 245, grifo meu). O pai é esse exceder interior, esse símbolo que faz com que possamos ir além de nós mesmos, conectando-nos com o Outro.

Se o pai era antes tomado como imago, aqui ele passa a ser símbolo, um símbolo que libera o sujeito da clausura imaginária. Note-se que, ao mesmo tempo em que abre para o sujeito um leque de significações novas, o simbólico também o obriga a se assujeitar a uma regra compartilhada, impondo-lhe uma perda de satisfação. O símbolo como morte da coisa pode ser lido retroativamente em termos do sacrifício do gozo que ele impõe: ao aceitar colocar-se sob a autoridade do símbolo, a criança renuncia à satisfação do narcisismo primário.

\section{3) O PAI COMO SIGNIFICANTE NA TEORIA ESTRUTURAL}

Embora referências à antropologia estrutural de Lévi-Strauss já possam ser detectadas na obra lacaniana desde o período anterior, tais menções desempenham naquele momento um papel secundário, ofuscadas que estavam pela referência maior à teoria da intersubjetividade. A intervenção maciça das teses da linguística estrutural e sua consequente releitura por Lacan se dará a partir da segunda metade dos anos 50 e terá evidentemente impactos importantes sobre a concepção da função paterna. No Seminário 3 (LACAN, 1955-56/2002), assistimos ao laborioso percurso de fundação do conceito de Nome do pai à luz da teoria do significante.

Um primeiro ponto a ser situado é que a noção anterior de símbolo vai sendo gradualmente ultrapassada pela de significante. Até então, o símbolo ainda poderia ser entendido como supondo uma correlação possível entre o som e o sentido, sem que qualquer primazia fosse concedida a uma ou outra dimensão. Com isso, a teoria corria o risco de recair numa interpretação expressiva do significante, na qual este possuiria, senão de fato, pelo menos de direito, um significado capaz de lhe fornecer uma garantia. Não por acaso, a psicanálise pôde ser concebida em certo momento do ensino de Lacan (1953-54/1983, p. 223) como completa reintegração da história do sujeito. Porém, a partir do momento em que Lacan afirma que "o significante, enquanto tal, não significa nada" (1955-56/2002, p. 209), a possibilidade de uma correlação harmônica entre significante e significado fica definitivamente excluída.

Um bom ponto de partida para abordar o Nome do pai como significante seria a consideração das três experiências fundamentais que, conforme Lacan (1955-56/2002), representariam eventos extremamente 
problemáticos para qualquer sujeito. Tais experiências estão todas ligadas, não por acaso, ao ponto em que linguagem e corpo humano se entrecruzam. São elas: o sexo, a morte e o nascimento. O sujeito histérico é testemunha viva da pergunta sobre a diferença sexual: sou homem ou mulher? Por sua vez, o obsessivo é notório por problematizar a própria materialidade da sua existência: estou vivo ou morto? Por último, o nascimento, o fato de se poder conceber outro ser humano, é também um ponto crucial para qualquer estrutura. Isso acontece porque a concepção não pode ser pensada exclusivamente como poder biológico de gerar outro ser, mas, como o próprio Lacan ressalta, valendo-se de uma expressão metafórica: trata-se na paternidade do "engendramento da alma, o engendramento do espírito pelo pai" (ibidem, p. 242). Ou seja, a gestação de outro ser não se dá apenas no plano material, mas principalmente no registro da palavra.

O fato é que tais experiências, para serem significadas, precisam ser metabolizadas pela ação de um significante fundamental. Esse significante, existente na neurose, é um significante especial, diferente dos outros. Lacan ressalta o papel desse significante na sustentação da trama da realidade; a sua ausência seria determinante para uma desorganização no plano da realidade: "na psicose, algo vem faltar na relação do sujeito com a realidade. Trata-se, com efeito, de uma realidade estruturada pela presença de um certo significante que é tradicional, herdado, transmitido" (LACAN, 1955-56/2002, p. 283).

O papel desse significante especial seria o de ser fonte da significação, garantindo que significante e significado possam se atar: "A noção do pai (...) dá a Freud o elemento mais sensível na experiência do que chamei o ponto de basta entre significante e significado" (ibidem, p. 303). Isso permite discernir o que pode acontecer na experiência psicótica: "Não é impossível que se chegue a determinar o número mínimo de pontos de ligação fundamentais entre o significante e o significado necessários para que um ser humano seja dito normal, e que, quando eles não estão estabelecidos, ou afrouxam, produzem o psicótico" (idem).

Quando há o significante paterno, o sujeito pode contar com um lugar para o qual ele pode endereçar uma questão sobre o seu ser. Não significa obviamente que ele obterá uma resposta definitiva ou satisfatória, mas que ele ao menos pode conseguir articular uma pergunta para um Outro suposto saber. Já o psicótico não poderia contar com tal lugar, a ponto de Lacan questionar: "Estamos certos de que os neuróticos se puseram uma questão. Os psicóticos, não é tão certo. A resposta lhes veio talvez antes da questão - é uma hipótese. Ou talvez a questão se pôs sozinha - não é impensável" (ibidem, p. 230).

Lacan cita o caso de um sujeito psicótico que cresce num lar anárquico e que se apega a um amigo, que se torna seu ponto de enraizamento na existência. Mas esse amigo finalmente se torna pai; nesse momento, o espelho se quebra, e o sujeito desestabiliza. Não por acaso, a experiência desencadeadora está ligada ao advento da paternidade. Nas circunstâncias de desencadeamento, um ponto que permaneceu fora da simbolização é mobilizado, sem que haja um significante para o qual o sujeito possa apelar a fim de tentar formular-lhe uma pergunta. Há aqui o sentimento de que o sujeito chegou à beira do buraco, o que deve ser tomado ao pé da letra: uma questão lhe vem de um ponto para o qual não há resposta. "Trata-se de conceber, não de imaginar, o que se passa para um sujeito quando a questão lhe vem dali onde não há significante, quando é o buraco, a falta que se faz sentir como tal" (LACAN, 1955-56/2002, p. 231).

Conforme Maleval (2002), temos neste seminário uma das primeiras formulações do Nome do pai, em que este é concebido como capitonado diacrônico: assim como a última palavra de uma frase sela o sentido em efeito retroativo, o Nome do pai seria um significante que se acrescenta a posteriori, conferindo sentido aos significantes que o antecederam. A capitonagem permitiria justamente a costura entre os domínios heterogêneos do significante e do significado. O efeito semântico da presença do significante paterno está aqui posto em primeiro plano.

Importa notar que, na cadeia S1-S2, está implícita uma assimetria entre os significantes: se o significante representa o sujeito para outro significante, temos que o primeiro exerce função de representação, ao passo que o segundo não representa o sujeito, mas é a instância graças à qual a representação se torna possível. O conjunto dos significantes representa o sujeito para o Nome do pai, que é o pólo para quem todos os outros podem representar algo. O Nome do pai é a condição que torna possível aos outros significantes representarem o sujeito. 
Um passo decisivo na construção do conceito de Nome do pai será dado no Seminário 4 (LACAN, 1956-57/1995), no qual se destacam dois pontos fundamentais: sua articulação com a noção linguística de metáfora e com a função do falo. É o que será desenvolvido a seguir.

Conforme Maleval (2002), a articulação do Nome do pai com a metáfora tornou-se possível a partir do encontro de Lacan com o trabalho de Jakobson (1956/1969) sobre as afasias. Tentemos entender de que forma Lacan se apropria dessa noção linguística.

A via mais simples para pensar a questão da metáfora paterna é retomar a tese lacaniana de que há um abismo irredutível entre as palavras e as coisas, de tal forma que o significante não encontra um objeto que lhe corresponda exatamente na realidade. $O$ significante mata a coisa enquanto um esteio ou base sólida exterior que pudesse lhe fornecer uma garantia, de tal forma que ele precisará recorrer a outros significantes a fim de encontrar sentido. "Nós sabemos que a entrada na ordem dos significantes pressupõe uma primeira metáfora que nega ativamente o laço causal entre o objeto e o signo" (VAN HAUTE, 2002). Ora, se o laço causal entre objeto e signo foi negado, o significante perdeu sua referência. Contudo, deve-se em seguida fazer um giro e entender que a referência do significante é a própria falta ou, em termos freudianos, o objeto perdido. A metáfora paterna tem como efeito o fato de a referência passar a ser o objeto perdido.

Nós podemos depois especificar essa primeira metáfora em uma perspectiva psicanalítica como a metáfora do Nome do pai: pois com base nessa metáfora a criança abandona a crença de há um objeto adequado que corresponda ao desejo da mãe. Assim como não existe um acoplamento entre o signo e o objeto que não seja ambíguo, também não existe acoplamento não ambíguo entre o desejo da mãe e os vários objetos que poderiam satisfazê-lo. Em outras palavras, com base na metáfora paterna a criança se rende ao movimento dos significantes. Ela desiste da esperança de algum dia se tornar apta a significar integralmente ou a realizar seu desejo. (VAN HAUTE, 2002).

O dizer se torna metafórico na medida em que é impossível para o sujeito ultrapassar a distância entre o significante e sua referência, dizendo literalmente o que quer. O significante só será capaz de dizer o objeto do desejo de forma oblíqua, figurada, conotativa, imprópria.

Esse é um sentido muito largo da expressão metáfora paterna. Aqui, o emprego da metáfora é um tanto impreciso, pois outras figuras de linguagem diferentes da metáfora também poderiam servir para indicar esse uso impróprio ou conotativo da linguagem. Há, porém, um uso mais restrito da metáfora em Lacan, mais próximo das proposições jakobsonianas. Vejamos.

Para Jakobson (1956/1969), o ato de fala exige dois tipos de operação realizados pelo indivíduo: a seleção dos termos entre as múltiplas alternativas oferecidas pelo código, e sua combinação em unidades maiores. A seleção intervém retendo um termo e descartando os demais, semelhantes ao termo escolhido sob um aspecto e diferentes quanto a outros aspectos. Por exemplo, digo casa, em vez de dizer cabana, choupana, mansão etc. Estes termos formariam uma família paradigmática, já que são termos suscetíveis de se substituir mutuamente. A seleção incide, então, sobre subregiões do código, sobre campos restritos dentro do mesmo. Como diz Jakobson, "num grupo de substituição os signos estão ligados entre si por diferentes graus de similaridade, que oscilam entre a equivalência dos sinônimos e o fundo comum (common core) dos antônimos" (JAKOBSON, 1956/1969, p.40).

Em que consiste a operação metafórica? A novidade da metáfora consiste justamente em criar uma semelhança entre dois termos até então pertencentes a campos semânticos distintos. Por exemplo, em A mulher é uma flor, há metáfora porque alguém, mostrando uma propriedade comum entre os dois termos (por exemplo, a delicadeza de ambos), conseguiu torná-los suscetíveis de se substituírem, fazendo com que um migrasse para a família paradigmática do outro. Se os termos em questão passam a poder alinhar-se no mesmo eixo paradigmático, temos, portanto, como primeira característica da metáfora, o fato de um significante poder ser substituído por outro.

Segundo a linguística, o critério autorizando a substituição de um termo por outro seria a existência de uma similaridade entre eles. No caso examinado anteriormente, observamos que mulher e flor possuíam como característica comum a delicadeza de ambas. Note-se que a similaridade é produzida pela operação metafórica, não existindo previamente a esta. A metáfora é uma inovação do paradigma precisamente por tornar semelhantes dois 
termos cuja aproximação nunca havia sido feita antes. Desse modo, embora seja condição da operação metafórica, a similaridade não preexiste à mesma, podendo ser verificada apenas a posteriori. A metáfora é um ato de criação justamente por propor a existência de uma semelhança ali onde não se suspeitava sua existência. Temos, portanto, como segunda característica da metáfora, a equivalência entre os significantes.

Lacan transpõe esse raciocínio a fim de pensar o complexo de Édipo. Se o Nome do pai implementa uma metáfora, ele deve tornar possível uma operação em que termos diferentes são tornados semelhantes ou equivalentes. Quais seriam esses termos heterogêneos que o Nome do pai permite amarrar? O que o Nome do pai possibilita é o estabelecimento de uma equivalência entre o objeto $x$ do Desejo da Mãe e o Falo. O Desejo da Mãe, outrora tomado pela criança como um impulso caprichoso e sem lei, passa a ser interpretado a partir da lente fálica, graças a uma costura artificial possibilitada pelo Nome do pai. A função do pai é então metaforizar o desejo da mãe no duplo sentido acima exposto, de Ihe assegurar um equivalente e assegurar que este equivalente seja apenas um substituto.

Isso acarreta a introdução de uma nuance na primeira formulação do Nome do pai. Se, no Seminário 3, o acento era posto pura e simplesmente sobre o efeito de significação promovido pelo significante paterno, o que está em jogo no Seminário 4 é o efeito de significação fálica. Esse acréscimo é de suma importância, pois joga luz sobre algo que é da ordem de um efeito inconsciente da função paterna. Isso quer dizer que, quando o sujeito escutar um determinado enunciado, a enunciação inconsciente que o suporta poderá ser decifrada em termos fálicos. Para além do que a cadeia pode transmitir em termos de conteúdos manifestos, o sujeito ganha condições de interpretar a enunciação latente que lhe subjaz sob a perspectiva fálica. "É isso que se lê nas entrelinhas, que Ihes permite não identificar o Outro com seus enunciados, ou seja, supor que, nos enunciados do Outro, outra coisa circula" (SOLER, 2015, p. 63).

Note-se como aqui também começa a ficar mais claro outro aspecto pouco explorado anteriormente: ao passo que, no seminário das psicoses, a formulação do pai como ponto de basta colocava em primeiro plano a cadeia de significantes em seu aspecto horizontal e linear, a partir do Seminário 4 a função do pai como metáfora acrescenta àquela uma leitura vertical ou em profundidade da cadeia, colocando em cena a articulação entre enunciado e enunciação.

O que seria a leitura do desejo do Outro em termos fálicos? No Seminário 4, o falo aparece articulado ao registro imaginário. Isso remonta à primeira leitura que uma criança faz do discurso dos seus pais, pela via de uma interpretação imaginária da falta: ela acredita na miragem de um Eu ideal, gestalt que supostamente completaria o desejo materno. Essa forma majestosa, que acena com a sua presença fascinante, é, na verdade, algo que se furta.

Em certos momentos essenciais do desenvolvimento, é como se a criança percebesse não haver para a mãe um encobrimento total, perfeito, fixo, entre ela e a imagem fálica, a qual poderia deslocar-se e iluminar outro ser em deficiência da mesma imagem. (MILLER, 1997, p. 500).

O sinal negativo do $-\phi$ pode indicar duas coisas: tanto que a imagem ideal está sempre ausente do campo especular, na medida em que se furta à apreensão pelo sujeito, quanto que a imagem de si só se apresenta no campo especular marcada por um déficit em comparação com a imagem ideal. $O$ falo seria aqui entendido como imagem ausente no campo especular que supostamente satisfaria o desejo do Outro.

A partir do Seminário 5 (LACAN, 1957-58/1999), o Falo já será situado simbolicamente como significante do desejo. O significante do desejo deve ser aqui entendido de 2 formas. Em sua vertente positiva, ele é aquele que fornece uma orientação para o desejo, indicando os objetos imaginários que seriam supostamente adequados para saciá-lo. Por exemplo, se a beleza tem para o sujeito o valor de significante fálico, tal marca o encaminhará inconscientemente em sua eleição erótica, reconhecendo alguns objetos como passíveis de despertar seu desejo e descartando outros. Já em sua vertente negativa, o significante fálico também reassegura a falta constitutiva do desejo: uma vez que ele necessariamente se dirige a um outro significante, salvaguarda assim a impossibilidade de detenção do desejo em um objeto imaginário específico. O Falo é então o significante do que falta ao Outro. Ao 
responder o que falta ao Outro, o significante fálico permite também responder o que faz falta ao sujeito: afinal, este deseja o desejo do Outro. Em suma, a função do Nome do pai é a de fornecer uma resposta ao desejo da Mãe pela via de significantes que tenham valor fálico (rico, bonito, inteligente etc.), que darão uma direção ao desejo, ao mesmo tempo em que preservam sua falta constitutiva, permitindo seu relançamento.

\section{4) LIMITES DA DEFINIÇÃO E DESDOBRAMENTOS POSTERIORES}

Seguindo a orientação de Maleval (2002), é possível afirmar que o Lacan dos anos 50 coloca em relevo o Nome do pai como garante da verdade, um Outro que assegura a consistência do conjunto dos significantes. É somente a partir do final dos anos 50 que o Outro passa a ser pensado como lugar de uma falta, e não mais como fiador da boa fé do sujeito.

Uma formulação que condensa o teor das contribuições dos anos 50 sobre a questão é a que se encontra na Questão preliminar: o Nome do pai é "o significante que, no Outro como lugar do significante, é o significante do Outro como lugar da lei" (LACAN, 1957-58/1998, p. 590). Ele é aqui tomado como o Outro do Outro, o Outro da Lei que pode dar consistência ao Outro como conjunto dos significantes. Apesar de sumarizar de forma clara as elaborações dos anos 50, essa definição terá depois de ser revista por Lacan. Pretende-se aqui elencar dois pontos que colocam dificuldades a tal definição.

O primeiro diz respeito a formulações com que a teoria lacaniana será confrontada ao se deparar com os ensinamentos da lógica moderna e da teoria dos conjuntos. Conforme examinamos, o Nome do pai desempenha o papel da Lei por ser um pólo ordenador da cadeia. Ao passo que todos os outros significantes têm a missão de receberem significação, a do Nome do pai é a de ser o doador da significação. Ele deveria, portanto, estar situado fora do conjunto dos significantes, constituindo um significante exterior que fornece a consistência do conjunto. Ele seria a condição que torna possível a existência do conjunto dos significantes como totalidade; por ser uma condição de existência do conjunto, não poderia consequentemente estar contido como elemento do conjunto. Ou seja, teríamos aí um conjunto incompleto, ao qual está faltando um significante que foi posto fora (Todo incompleto).

Por outro lado, se o Nome do pai fosse um significante como outro qualquer, ele poderia estar incluído no conjunto. Nada impediria que ele pudesse ser, por exemplo, significado por outros. O que aconteceria então se nós decidíssemos incluir tudo, não deixando nenhum significante fora do conjunto, retirando qualquer exceção a the fazer limite? O preço a pagar seria a perda do próprio Todo, pois não haveria mais a instância para a qual cada um dos significantes pudesse se reportar e que consistiria o ponto de unidade entre eles, o ponto de referência comum que impede sua dispersão.

Ora, como não ver que a hipótese da Questão preliminar, segundo a qual o Outro como lugar dos significantes inclui o Outro como lugar da Lei, entra em choque frontalmente com esses desenvolvimentos, uma vez que postula uma totalidade completa? Na verdade, só temos logicamente duas possibilidades: na primeira alternativa, o preço a pagar para alcançar o Todo é arcar com um elemento que destotaliza o conjunto ao ser posto fora dele (Todo incompleto); já na segunda alternativa, o preço a pagar para que não reste nenhum elemento fora é arcar com o desfazimento da própria unidade do conjunto (não-Todo). Não há, portanto, um Todo que seja ao mesmo tempo completo e consistente. Essa é uma das mais fortes razões que levarão Lacan a elaborar a tese de uma falta no campo do Outro, o qual deixará de ser considerado como totalidade auto-inclusiva no final dos anos 50.

Isso acarreta consequências para a função paterna. Se o Outro da Lei passa a ocupar um lugar de exceção diante do Outro do significante, convém destacar que se trata de uma exceção fictícia e artificial, pois não tem nenhuma fundamentação que a legitime. A Lei, no fundo, repousa sobre uma impostura: a palavra de autoridade não tem como fiadora uma justificativa racional suficiente, ela tem como garantia apenas a sua própria enunciação (LACAN, 1960/1998).

Um segundo ponto que levará Lacan a um questionamento da posição anterior diz respeito diretamente à clínica, mais precisamente aos limites da resposta fálica para dar conta da questão sobre o desejo. Uma vez que não existe um significante último capaz de fornecer a chave do desejo do Outro, este permanece, em última instância, 
enigmático: não se sabe o que o Outro quer dizer com o que diz. Há uma incógnita que persiste radicalmente para além de qualquer significante particular que tente responder ao Che vuoi?.

Apesar de proporcionar uma valiosa resposta da qual o sujeito pode se servir para se safar do obscuro capricho da mãe, o significante fálico é, no final das contas, uma resposta encobridora. Ele tem o valor de um véu apaziguador, que oculta a permanência de um resto não inteiramente decifrável no desejo do Outro. Esse resto aponta claramente para um limite da função paterna. Como sublinha Tendlarz: “A metáfora paterna sempre fracassa - caso contrário não existiriam os sintomas -, há um resto do desejo do Outro, ele me disse isso, mas o que ele quer, há um resto ineludível da metáfora paterna, aquilo que não passa pelo significante" (TENDLARZ, 2009, p. 30). A operação paterna só pode servir ao sujeito até certo ponto. Lacan será levado então a grafar o $S(A)$ como o significante de uma falta no Outro.

Apesar dos desdobramentos posteriores do conceito, é importante ressaltar que o Nome do pai é um operador psíquico do qual o neurótico pôde se servir em sua constituição. Se "estamos certos de que os neuróticos se puseram uma questão" (LACAN, 1955-56/2002, p. 230), isso somente ocorre porque o pai proporciona a condição a partir da qual colocar uma questão se torna possível. Já os limites do pai proporcionam a condição para que algo dessa questão chegue a um fim e o término da análise seja possível.

Recebido em: 25 de julho de 2016. Aprovado em: 25 de janeiro de 2017.

\section{REFERÊNCIAS}

JAKOBSON, R. Linguística e comunicação (1956). São Paulo: Cultrix, 1969.

LACAN, J. A relação de objeto (1956-1957). Rio de Janeiro: Jorge Zahar, 1995. (O seminário, 4). . As formações do inconsciente (1957-1958). Rio de Janeiro: Jorge Zahar, 1999. (O seminário, 5). As psicoses (1955-1956). Rio de Janeiro: Jorge Zahar, 2010. (O seminário, 3).

De uma questão preliminar a todo tratamento possível da psicose (1957-1958). In: Escritos. Rio de Janeiro: Jorge Zahar, 1998 O eu na teoria de Freud e na técnica da psicanálise (1954-1955). Rio de Janeiro: Jorge Zahar, 2010. (O seminário, 2).

. Os complexos familiares na formação do indivíduo (1938). In Outros escritos. Rio de Janeiro: Jorge Zahar, 2003. . Os escritos técnicos de Freud (1953-1954). Rio de Janeiro: Jorge Zahar, 1983. (O seminário, 1). . O sinthoma (1975-1976). Rio de Janeiro: Jorge Zahar, 2007. (O seminário, 23).

Subversão do sujeito e dialética do desejo no inconsciente freudiano (1960). In: Janeiro: Jorge Zahar, 1998.

MALEVAL, J. C. La forclusión del Nombre del Padre: el concepto e su clínica. Buenos Aires: Paidós, 2002.

MILLER, J. A. Lacan elucidado. Rio de Janeiro: Jorge Zahar,1997.

SOLER, C. A paranoia no ensino de Jacques Lacan. In: QUINET, A. (org.). Na mira do outro: a paranoia e seus fenômenos. Rio de Janeiro: Contra Capa, 2015.

TENDLARZ, S. Psicosis: lo clásico y lo nuevo. Buenos Aires: Grama Ediciones, 2009.

VAN HAUTE, P. Against adaptation: Lacan`s subversion of the subject. Nova lorque: Other Press, 2002.

\section{Rosane Zétola Lustoza}

rosanelustoza@yahoo.com.br 